\title{
Posterior interosseous flap for resurfacing posttraumatic soft tissue defects of the elbow
}

\author{
Soufiane Aharram*, Yahyaoui Mounir, Jawad Amghar, Mohammed Benhamou, Omar Agoumi and Abdelkarim Daoudi \\ Department of Traumatology-Orthopedics, CHU Mohammed VI, Oujda, Morocco
}

\begin{abstract}
The posterior interosseous flap is recommended in surgery of the hand for its fineness and the length of its pedicle. The coverage of elbow loss requires a simple and versatile flap with good functional and aesthetic results. We report a case of post-traumatic elbow loss in a young adult with exposed osteosynthesis material. The technique used is the posterior interosseous flap with proximal pedicle according to the seat of the region to be covered.
\end{abstract}

\section{Introduction}

The posterior interosseous flap described for the first time in 1986 is a pedicle flap of the forearm islet, which can be taken directly or retrograde $[1,2]$. It is vascularized by arterioles with cutaneous destinies, in variable number, coming from the posterior interosseous artery [3].

Posterior vascularized interosseous flap at the expense of the posterior pedicle, which gives septal arterioles for the skin covering the entire length of its path.

The posterior interosseous flap was used either with a direct pedicle to cover the filling of the elbow substance with anterograde flow, or with a retrograde pedicle to cover the loss of substance on the dorsal surface of the hand [4].

\section{Clinical case}

A 23-year-old female driver, with no particular antecedent, victim of a work accident following a fall from a power pole with a height estimated at $4 \mathrm{~m}$ with reception on the right hemi-body. The patient had severe trauma to the elbow with a floating elbow and a cutaneous opening stage 1 according to Cauchoix and Duparc on the posterior area of the elbow (Figure 1).

The patient received an X-ray of the arm and elbow face and profile, showing a fracture of the humeral diaphysis with a fracture of montegia elbow (Figures 2a,b).

The patient was admitted to the operating room under general anesthesia in left lateral decubitus. After trimming and washing the cutaneous wound. We began the osteosynthesis of the humerus by the placement of a DCP plate (dynamic compression plate), later by a trans-tricipital approach we discovered a comminuted fracture of the olecranon with dislocation of the radial head and fracture of the external condyle.

We reduced the dislocation and osteosynthesis of the external condyle by 2 screws of Herbert, afterwards we osteosynthesized the olecranon by 2 plates, a $1 / 3$ tube and the other special plate acetabulum and we finished the gesture by putting in place anchors on the lateral ligament and the ring ligament (Figures $3 \mathrm{a}, \mathrm{b}$ ). 3 weeks after the patient presented a loss of substance at the tip of the secondary olecranon

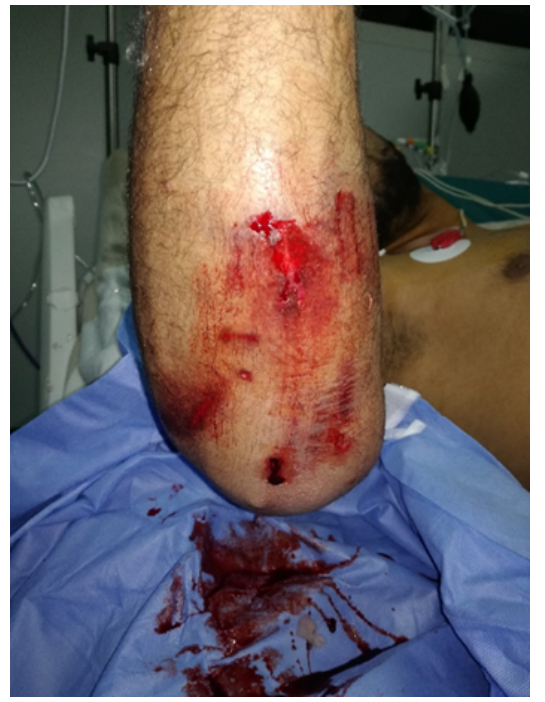

Figure 1. Clinical aspect of the elbow at the admission of the patient to the emergency

cutaneous necrosis with bare exposure of the osteosynthesis material (Figure 4).

The decision was to make a trimming with subsequently a gesture of cover. Therefore, we admitted the patient to the operating room under general anesthesia in supine position, pneumatic tourniquet at the root of the limb, after excision of doubtful and mortified tissues, we have located the sampler site at the dorsal surface of the right arm (Figures 5a,b).

Circumferential cutaneous and subcutaneous incision of the pallet and zigzag out towards the site of grafting and detachment of the fascia

${ }^{\star}$ Correspondence to: Soufiane Aharram, Department of TraumatologyOrthopedics, Faculty of Medicine and Pharmacy of Oujda, Mohammed First University Oujda, Morocco, E-mail: aharram.1993@gmail.com

Key words: elbow trauma, posterior interosseous flap with proximal pedicle, floating elbow

Received: May 06, 2019; Accepted: May 27, 2019; Published: May 30, 2019 


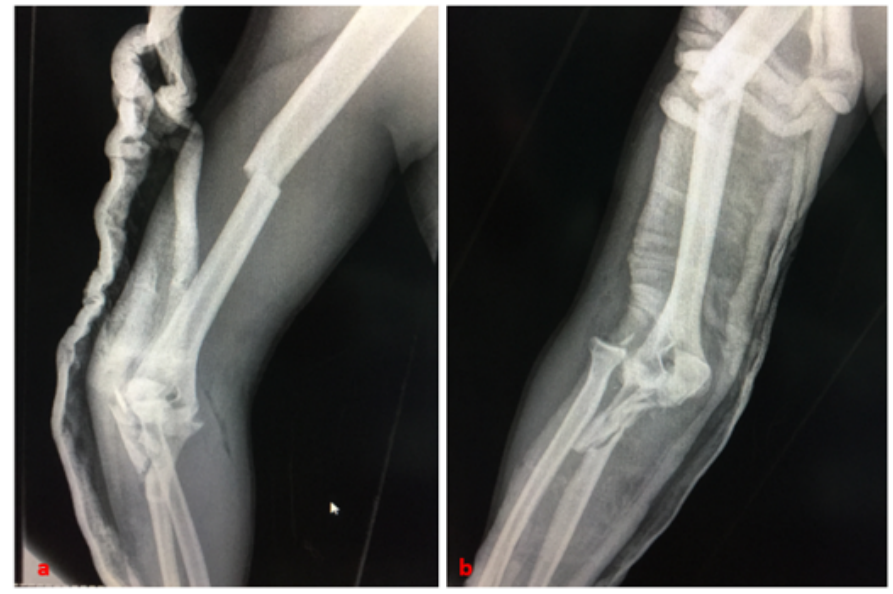

Figures 2a,b. Radiograph of the arm face and profile showing a medio diaphyseal fracture of the humerus, with fracture of montégia at the elbow
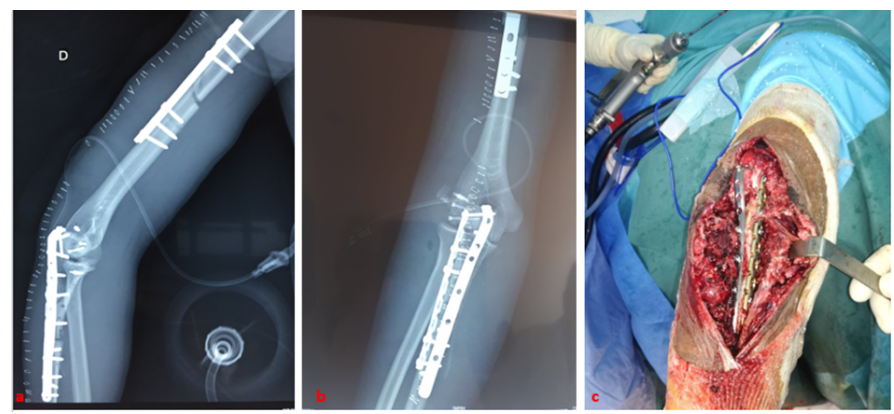

Figures 3a-c. Osteosynthesis of the diaphyseal fracture of the humerus by a DCP plate, with osteosynthesis of the montégia fracture

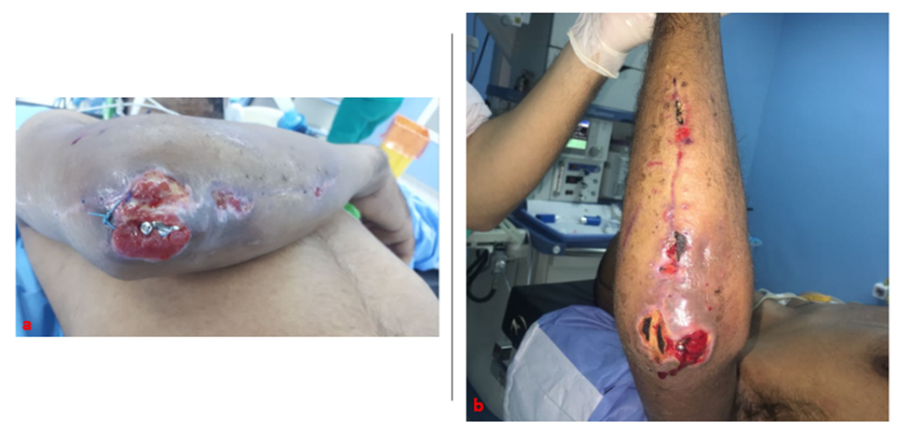

Figures 4a,b. Exposure of osteosynthesis material to the elbow
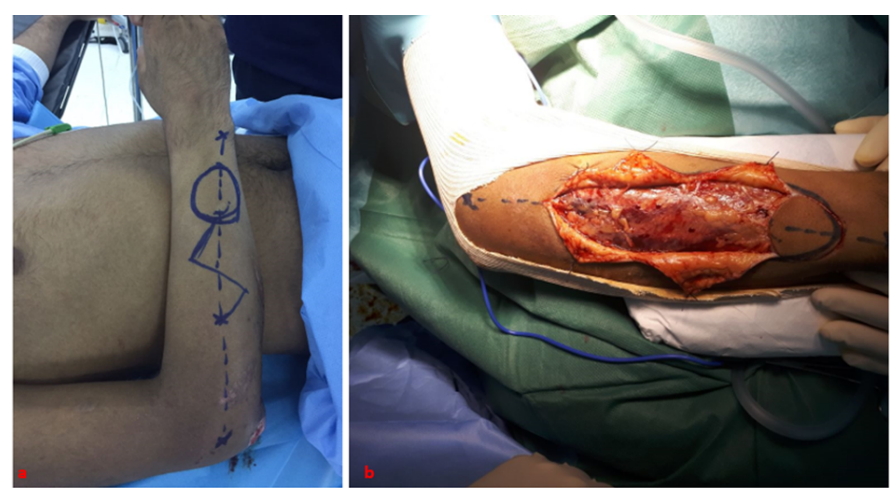

Figures 5a,b. Identification of the sampler site on the dorsal aspect of the fore arm
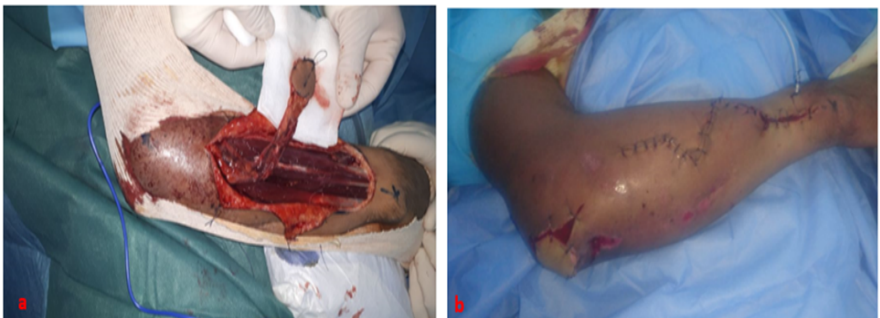

Figures 6a,b. a: Detachment of the fascia with its pedicle to the flap removed and placement of the flap and coverage of the osteosynthesis material of the exposed elbow, after having tunneled and move subcutaneously, $\mathbf{b}$ : fixation flap by simple stitches

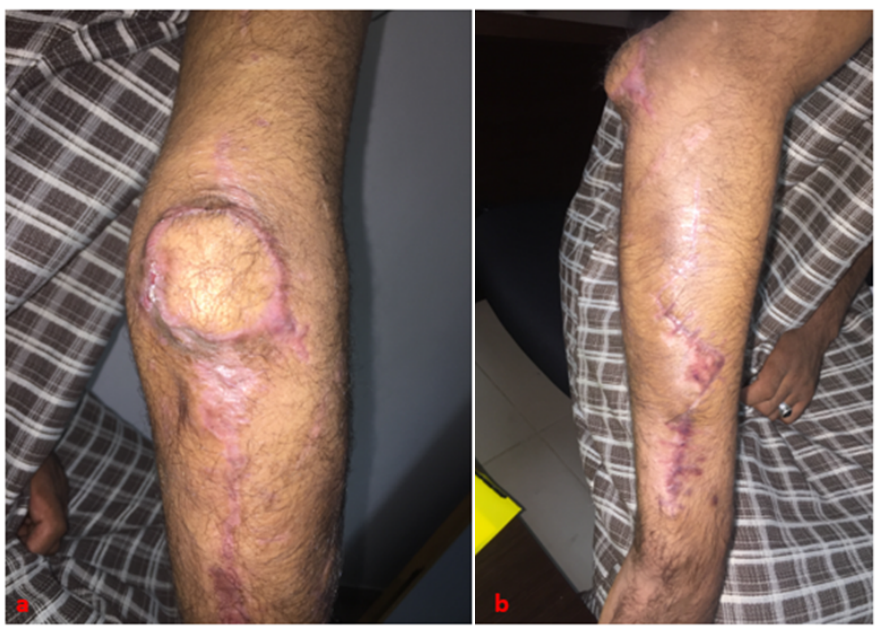

Figures 7a,b. Healed flap without signs of pain and coverage of osteosynthesis material

with its pedicle towards the flap taken then installation of the flap and cover of the material of osteosynthesis of the elbow exposed, after the Having tunneled and moved subcutaneously, the flap is then fixed by simple stitches (Figures 6a-c). Postoperatively, an immobilization of the elbow in extension to keep the viability of the elbow.

The evolution was satisfactory, the flap healed without any sign of suffering (Figures 7a,b). Upon healing, the patient was referred to the rehabilitation center.

\section{Discussion}

The posterior interosseous flap is part of the techniques for recovering loss of substance in the upper limb. Etiologies leading to the use of this type of flap are essentially represented by traumatic lesions such as crushing or skin erosion and more rarely by burns sequelae $[5,6]$.

The reliability of the posterior interosseous flap is not absolute. Indeed, no reliable examination can detect during the preoperative period the integrity of the posterior interosseous artery or the existence of a distal anastomosis: the Doppler specificity is not absolute and arteriography is an invasive examination and difficult to interpret for arteries of this caliber [6].

The vascular anatomy of the flap refers to the posterior interosseous pedicle, septocutaneous perforators, and proximal and distal anastomoses of the posterior interosseous artery [7]. All these anatomical variations must favor the primary research of the pedicle before incision of the pallet of the flap, or even justify for some the recourse to a preoperative ultrasound $[2,8]$. 
In the panoply of loco-regional flaps, the posterior interosseous flap presents the interest of not sacrificing an artery essential to the vasculature of the hand.

\section{Conclusion}

The posterior interosseous flap is a versatile and reliable flap for the coverage of hand and wrist defects, including small lesions allowing direct closure of the donor site.

\section{Conflicts of interest}

The author does not declare any conflicts of interest.

\section{Author contribution}

All authors contributed to the conduct of this research and read and approved the final manuscript.

\section{References}

1. Masquelet AC, Penteado CV (1987) Posterior interosseous flap. Ann Chir Main 6: 131-139.

2. Zancolli EA, Angrigiani C (1986) Dorsal flap of the forearm. Rev Asoc Arg Ortop Traumatol 51: 161-168.

3. Penteado CV, Masquelet AC, Chevrel JP (1986) The anatomic basis of the fasciocutaneous flap of the posterior interosseous artery. Surg Radiol Anat 8: 209-215.

4. Ahmet E, Ibrahim T, Omer E (2003) Posterior interosseous artery flap in traumatic hand injuries. Arch Orthop Trauma Surg 123: 323-326.

5. Balakrishnan G, Kumar BS, Hussain SA (2003) Reverse-flow posterior interosseous artery flap revisited. Plast Reconstr Surg 111: 2364-2349.

6. Mazzer N, Barbieri CH, Cortez M (1996) The posterior interosseous forearm island flap for skin defects in the hand and elbow. A prospective study of 51 cases. $J$ Hand Surg 21: $237-243$.

7. Buchler U, Frey HP (1991) Retrograde posterior interosseous flap. J Hand Surg 16 : 283-292.

8. Puri V, Mahendru S, Rana R (2007) Posterior interosseous artery flap, fasciosubcutaneous pedicle technique: A study of 25 cases. J Plast Reconstr Aesthet Surg 60: 1331-1337.

Copyright: $(02019$ Aharram S. This is an open-access article distributed under the terms of the Creative Commons Attribution License, which permits unrestricted use, distribution, and reproduction in any medium, provided the original author and source are credited. 